\title{
The Outcome of Immediate or Delayed Application of a Single-Step Self-Etch Adhesive to Coronal Dentin Following the Application of Different Endodontic Irrigants
}

\author{
Shehab-El Din Mohammed Saber ${ }^{a}$ \\ Farid Sabry El-Askary ${ }^{\mathrm{b}}$
}

\begin{abstract}
Objectives: The aim of this study was to evaluate the outcome of immediate or delayed bonding of a single-step self-etch adhesive to coronal dentin after the application of different endodontic irrigants.

Methods: Thirty five human molars were used. The coronal dentin was irrigated with either $0.9 \%$ physiologic saline (NS), $2 \%$ Chlorhexidine gluconate (CHX) or $2.5 \%$ commercially used sodium hypochlorite $(\mathrm{NaOCl})$. Composite cylinders were bonded with the coronal dentin using the Clearfil $\mathrm{S}^{3}$ bond, which was applied either immediately or after one week storage time following the irrigation procedures. Shear bond strength testing was performed at a cross-head speed of $0.5 \mathrm{~mm} / \mathrm{min}$, and the resin/dentin interface was evaluated using SEM.

Results: Irrigation with NS, CHX, or NaOCL followed by immediate adhesive application resulted in a reduction in the shear bond strength values recorded and this was statistically significant in comparison with the control group $(P<.05)$. However, delaying the adhesive application resulted in a statistically significant $(P<.05)$ improvement in the shear bond strength recorded in specimens irrigated with NS and $\mathrm{CHX}$ only.

Conclusions: Delaying the bonding procedures for one week appeared to be beneficial in improving the shear bond strength of Clearfil $\mathrm{S}^{3}$ bond with coronal dentin especially when $\mathrm{NS}$ and $\mathrm{CHX}$ were used as endodontic irrigants. $\mathrm{NaOCL}$ proved to be an incompatible irrigating solution when used prior to the application of such adhesive. (Eur J Dent 2009;3:83-89)
\end{abstract}

Key words: Irrigating solutions; Self-etching adhesive; Bond strength; Coronal dentin.

- a Lecturer, Endodontic Department, Faculty of Dentistry, Ain Shams University, Cairo, Egypt.

b Associate Professor, Operative Dentistry Department, Faculty of Dentistry, Ain Shams University, Cairo, Egypt.

- Corresponding author: Farid Sabry El-Askary Operative Dentistry Department, Faculty of Dentistry,

Ain Shams University, Cairo-Egypt.

Phone : 0020102500177 Fax: 0020226820191

E-mail: faridelaskarylahotmail.com

\section{INTRODUCTION}

It has been proven that the quality of the permanent coronal restoration has a great influence on the overall prognosis of endodontically treated teeth. ${ }^{1-5}$ In contemporary dental practice, the opportunity of restoring such teeth with resin composite has been increased as a result of the continuous revolution in the adhesive systems formulation. Bonded resin 
restorative materials permit transmission of functional stresses across the bonded interface to the tooth, with the potential to reinforce the weakened tooth structure..$^{6,7}$

Nevertheless, chemical irrigants employed during root canal treatment to provide gross debridement, lubrication, destruction of microbes, and dissolution of tissues, result in alteration of the chemical and mechanical characteristics of dentin, which affects its interaction with the restorative materials used for coronal sealing. ${ }^{8}$ The most commonly used irrigating solutions are Sodium hypochlorite ( $\mathrm{NaOCl}$ and Chlorhexidine gluconate (CHX). $\mathrm{NaOCl}$ has a unique tissue solvent ability in addition to its well documented potent antimicrobial activity. While $\mathrm{CHX}$, being similarly antibacterial and relatively non-toxic to the periapical tissues forms an alternative irrigant to sodium hypochlorite. ${ }^{9}$

The adverse effects of $\mathrm{NaOCl}$ on resin-dentin bond have been investigated previously. ${ }^{8,10-}$ ${ }^{14}$ Although the effect of $\mathrm{CHX}$ on resin/dentin adhesion is still unclear, ${ }^{15}$ recent studies reported that $\mathrm{CHX}$ could prevent the degradation of the collagen fibres and preserve the integrity of the hybrid layer. ${ }^{16-18}$

The self-etching approach is based on simultaneous conditioning and priming of dentin with incorporation of the smear layer within the hybridized complex. ${ }^{19,20}$ The single-step selfetching adhesives are less technique sensitive and less time consuming compared with their multi-step counterparts. This might be of an importance, especially for the busy dental practitioners. ${ }^{21}$

The permanent restoration can be applied immediately after completion of endodontic treatment, or can be postponed for some time and a temporary restoration is used to seal the access cavity. The question then arises: would such a delaying in the bonding procedures affect the resin/dentin bond strength?

The purpose of this study is to evaluate the outcome of either immediate or delayed application of a single-step self-etching adhesive to coronal dentin after the application of different endodontic irrigants. The null hypothesis tested is neither irrigating solutions nor application time has an influence on the shear bond strength of the single-step selfetching adhesive to coronal dentin.

\section{MATERIALS AND METHODS}

Teeth selection

Thirty five human molars extracted for periodontal reasons, and stored in $0.5 \%$ thymol solution at $4^{\circ} \mathrm{C}$ for not more than one month were used in this study. Twenty eight teeth were used for shear bond strength testing and seven teeth were used for SEM evaluation.

\section{Grouping of specimens}

Each tooth was sectioned mesio-distally down to the root using a diamond disc mounted on a low speed contra angle with a copious air-water spray. After sectioning, the seventy halves were divided into 60-experimental and 10-control specimens. The experimental specimens were subdivided into three equal groups representing the three tested irrigants; $0.9 \%$ physiologic saline solution (NS, Al Mottahedoon Pharma, $10^{\text {th }}$ Ramadan City, Cairo-Egypt. Lot \# 61212), $2 \%$ Chlorhexidine gluconate in water solution (CHX, Cairo Pharmaceuticals, Cairo-Egypt, Lot \# 2005323), and 2.5\% commercially used sodium hypochlorite solution. Each group was further subdivided into two equal subgroups according to the adhesive application time, either immediate or delayed for one week after completion of the irrigating procedures.

\section{Preparation of specimens}

Each specimen was encircled with a rectangular mould (Figure $1 \mathrm{~A}$ ) into which autocured acrylic resin (Acroston, under exclusive license of Acroston Dental Company-Cairo, Egypt) was poured. The control specimens were fixed on the base of the mould from their dentin side using a double face adhesive tape. While the experimental specimens were fixed using a double layer of pink wax in order to create artificial side walls (Figure 1B). After setting of the acrylic material, both the adhesive tapes and the pink wax were removed. The coronal dentin was wet ground using a high speed abrasive bur (016, 6835 KR. Komet, USA) with gentle pressure for 5 seconds in one direction to create a smear layer. The dentin surfaces were rinsed with copious air-water spray for 10 seconds and 
the specimens were stored in distilled water at room temperature.

Application of the irrigating solutions and bonding procedures

The coronal dentin of the control specimens were restored directly without the use of the different irrigants. A single-step self-etching adhesive, Clearfil $S^{3}$ bond in a single-dose form, (Kuraray Medical INC, Okayama, Japan. Lot \# 00007B] was applied according to the manufacturer's instructions. The self-etching adhesive was applied with gentle agitation using the supplied micro-brush and left undisturbed for 20 seconds. The adhesive was then air-dried with high pressure oil-water free compressed air for 5 seconds and light cured for 10 seconds using a halogen light curing unit (Cromalux-E, Meca-Physik Dental Division, Rastatt, Germany) with an output of $600 \mathrm{~mW} / \mathrm{cm}^{2}$.

The experimental specimens were irrigated with $10 \mathrm{ml}$ of each irrigant for 20 minutes. The solution was renewed every 2 minutes so that the dentin surface was kept moist throughout this period. After being rinsed with $10 \mathrm{ml}$ distilled water, half of the specimens received immediate adhesive application as for the control specimens, while the other half were sealed with sterile cotton and a temporary restorative material (Coltosol, Coltene G, Altsatten, Sweitzerland) and kept in an incubator in $100 \%$ relative humidity at $37^{\circ} \mathrm{C}$ for one week.

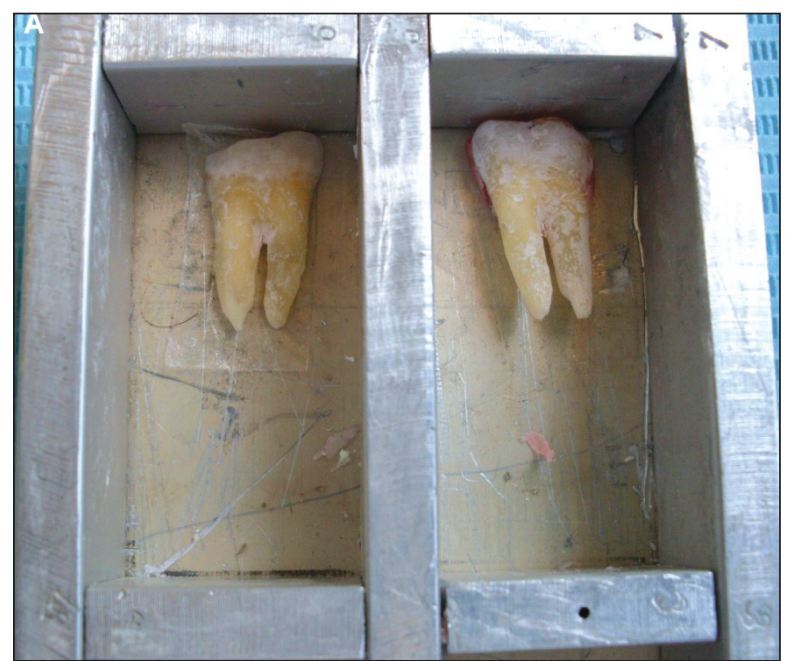

Figure 1A. The control specimen lied on its dentin side on double face adhesive tape (left) while the experimental specimen lied on double layer of pink wax to create artificial acrylic walls. Both specimens surrounded by a metallic rectangular mould on which the self-cured acrylic resin was poured.
After this period the temporary restorations were removed, the specimens were rinsed using copious air/water spray for 10 seconds and gently air dried for 5 seconds, before the application of the adhesive. The adhesive was applied as mentioned before. The irrigation and bonding procedures are summarized in Table 1.

A transparent polyvinyl tube $13 \mathrm{~mm}$ in diameter and $2 \mathrm{~mm}$ in length) was filled with resin composite material (TPH ${ }^{\mathrm{TM}}$ Spectrum, Shade A3, DENTSPLY, Konstanz, Germany, Lot \# E617014), placed over the cured adhesive, and the composite material was cured for 40 seconds. After curing of the composite material, the polyvinyl tube was cut using bard parker blade \#15 and the specimens were stored in distilled water for 24 hours.

\section{Shear bond strength testing}

For shear bond strength testing, 8-specimens form each group were used. Each specimen was mounted to a universal testing machine (Lloyd Instrument LR5K series- London, UK) and a chisel bladed metallic instrument was positioned as close as possible to the composite/ dentin interface from the occlusal enamel side, in which no artificial acrylic wall was present (Figure 1C). The test was run at a crosshead speed of $0.5 \mathrm{~mm} / \mathrm{minute}$ until failure. The load recorded in Newton was divided over the surface area and the shear bond strength was calculated in megapascal (MPa).

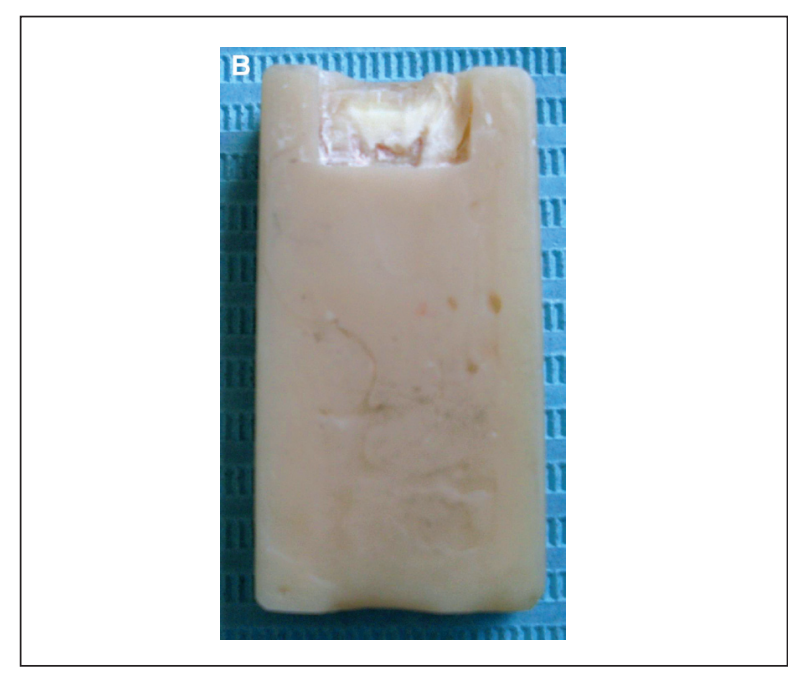

Figure 1B. The experimental specimen after hardening of the acrylic resin material shows the specimen surrounded by three artificial acrylic walls. 


\section{SEM preparation}

For SEM evaluation, 2- specimens were used from each group. After curing of the adhesive, a composite block approximately $2 \mathrm{~mm}$ in thickness was used to restore the coronal dentin and was cured for 40 seconds. The specimens were stored in distilled water for 24 hours. Each half was sectioned cervical to the composite block to separate the dentin surface with its attached composite material from the acrylic block. This procedure was done using diamond disc rotated at low speed with a copious air-water spray. Each separated half was further sectioned occluso-cervically into two halves, producing 4 specimens per group. The evaluated dentin surfaces were wet ground using 600, 1000 and 1200 grits SiC. The surfaces were acid etched using $35 \%$ phosphoric acid for 10 seconds, rinsed for 15 seconds and gently air dried. The samples were then immersed in $5.25 \%$ sodium hypochlorite for 120 seconds, washed under running water for 120 seconds and dried in ascending concentration of alcohol series of $50 \%, 70 \%, 90 \%$ for 20 minutes each and in $100 \%$ for one hour. The specimens were fixed with double-faced stickers on specimen holders, gold sputtered (BAL-TEC, SCD 005 sputter coater, Germanyl, and examined under SEM (Philips XL30, Holland), operated at $30 \mathrm{Kv}$.

\section{Statistical analysis}

All data were expressed as mean \pm standard deviation (SD) in MPa and were analyzed using one-way analysis of variance (ANOVA) followed by Tukey-Kramer multiple-comparison post hoc

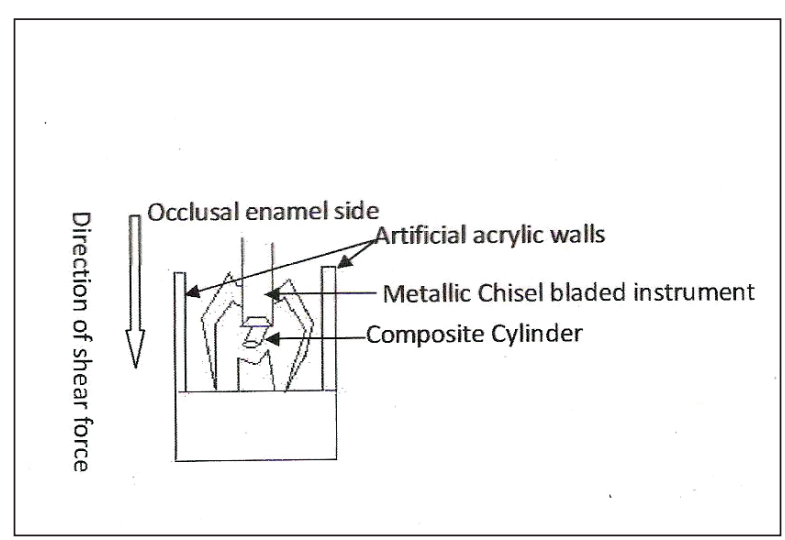

Figure 1C. Schematic diagram represents the direction of the applied shear force from the occlusal enamel side using the metallic chisel bladed instrument. test, which was used to compare the shear bond strength between groups. $\mathrm{P}<.05$ was considered significant.

\section{RESULTS}

The results of this study (Table 2), showed that irrigation with NS, CHX, or NaOCL followed by immediate adhesive application resulted in a reduction in the shear bond strength values recorded and this was statistically significant in comparison with the control group $(P<.05)$. However, delaying the adhesive application resulted in a statistically significant $(P<.05)$ improvement in the shear bond strength recorded in specimens irrigated with NS and CHX only.

Representative SEM images for groups $G 1$, G3, G4 and $G 6$ are presented in Figures 2, 3, 4 and 5 , respectively.

\section{DISCUSSION}

Resin composite restorations are used to restore the access cavity or to function as a foundation restoration in endodontically treated teeth. In both clinical cases it is very important to achieve an excellent bond with dentin. ${ }^{11}$ Loss of endodontically treated teeth due to improper coronal restoration has been reported to be more than the actual failure of the endodontic treatment. ${ }^{3}$

Although immediate sealing using restorative materials after completion of the endodontic treatment is a powerful tool in preventing early coronal leakage, ${ }^{15-17,22}$ the effect of delayed placement of adhesive restorations on the dentin

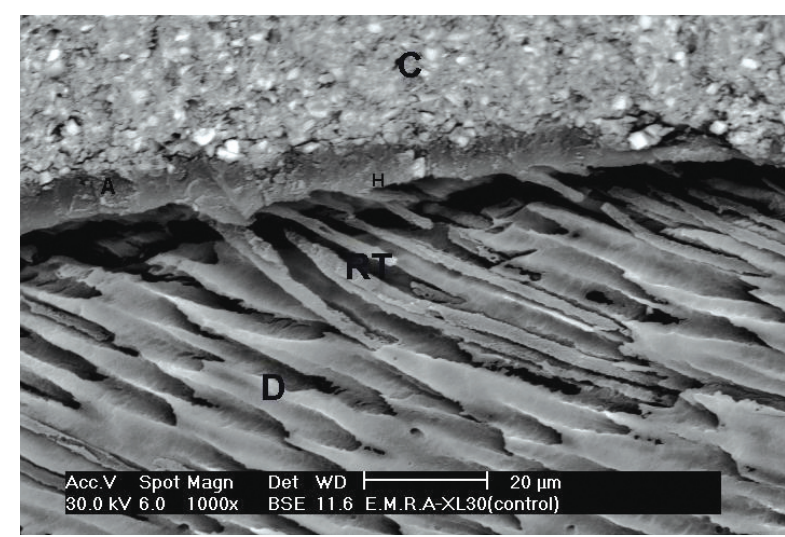

Figure 2. SEM micrograph for G1 (control) showing a continuous well defined Hybrid layer $(\mathrm{H})$ with incomplete resin infiltration. $\mathrm{D}=$ Dentin, $\mathrm{RT}=$ Resin Tags, $\mathrm{A}=$ Adhesive, $\mathrm{C}=$ Composite resin (Original magnification $\mathrm{X} 1000$ ). 
bond strength was not discussed extensively in the literature. This is an important gap in our knowledge; as such delaying process would affect the resin/dentin bond.

The use of self-etching adhesives offers some advantages over the use of the etch and rinse counterparts. Self-etching adhesives have weak acids in their primer composition, leading to less change in dentinal wall structure than the strong acids in the etch and rinse systems. Also collagen fibril collapse as a result of the air drying procedure after rinsing of acid is eliminated. ${ }^{23,24}$

Following the results of this study, the null hypothesis is rejected. The irrigating solutions and the time of adhesive application influenced the shear bond strength of Clearfil $\mathrm{S}^{3}$ bond to coronal dentin. Clearfil $\mathrm{S}^{3}$ bond is a mild singlestep self-etching adhesive $21,25,26$ with $\mathrm{pH} \geq 2 .{ }^{21}$ When the coronal dentin was irrigated with the

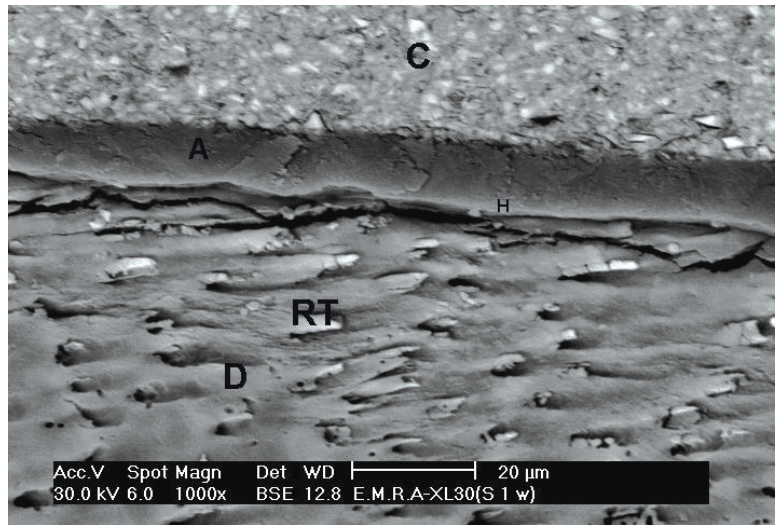

Figure 3. SEM micrograph for G3 (NS-delayed), showing a well defined Hybrid layer $(H)$ with the presence of resin tags infiltration (RT). A=Adhesive, $\mathrm{C}=$ Composite resin and $\mathrm{D}=$ Dentin (Original magnification $\mathrm{X} 1000$ ).

Table 1. Summary of irrigation and bonding procedures.

\begin{tabular}{cccc}
\hline Group & $\mathbf{N}$ & Irrigation & Adhesive application \\
\hline G1 & 10 & None (control) & Direct bonding \\
G2 & 10 & $0.9 \% \mathrm{NS}$ & Immediate \\
G3 & 10 & $0.9 \% \mathrm{NS}$ & Delayed \\
G4 & 10 & $2 \% \mathrm{CHX}$ & Immediate \\
G5 & 10 & $2 \% \mathrm{CHX}$ & Delayed \\
G6 & 10 & $2.5 \% \mathrm{NaOCl}$ & Immediate \\
G7 & 10 & $2.5 \% \mathrm{NaOCl}$ & Delayed \\
\hline
\end{tabular}

April 2009 - Vol.3 different irrigating solutions used and received immediate adhesive application, the bond strength was adversely affected. NS precipitates sodium and chlorine ions on dentin surface ${ }^{27}$ which might interfere with the bonding efficiency and resin infiltration of the Clearfil $\mathrm{S}^{3}$ adhesive. The significant improvement in the shear bond strength when the adhesive application was delayed could be attributed to the presence of numerous resin tags infiltration (Figure 3), which resisted the acute debonding stresses ${ }^{22}$ which could be occurred during bond strength testing. The presence of these numerous resin tags might be due to the elimination of the effect of the precipitated sodium and chlorine ions. This is an explanation that needs further investigation.

As $\mathrm{CHX}$ is a strong dicationic base with 2 positive charges on either side of the hexamethylene bridge, ${ }^{28}$ a strong electrostatic bond with the phosphate group of the hydroxyapatite might be formed. ${ }^{29}$ White et $\mathrm{al}^{30}$ and Leonardo et $\mathrm{al}^{31}$ have demonstrated that $\mathrm{CHX}$ adsorbs to and is released from dentin as long as 48 to 72 hours. The contamination of the dentin surface with irrigating residues and by-products might interfere with resin penetration into the demineralized dentin. ${ }^{32}$ This explanation confirmed our results, as the adsorption of $\mathrm{CHX}$ onto dentin interferes with immediate resin infiltration (Figure 4). This is in disagreement with Santos et $\mathrm{al}^{20}$ who reported that $\mathrm{CHX}$ did not affect the bond strength of the self-etch adhesive, Clearfil SE bond, to the pulp chamber dentin because it is a non-oxidizing agent. In this

Table 2. Means \pm Standard deviations (SD) in MPa of the shear bond strength of the different experimental groups.

\begin{tabular}{l|c|c|c|c} 
Group & Mean \pm SD & Tukey & Minimum & Maximum \\
\hline G1 & $26.38 \pm 5.26$ & A & 18.7 & 32.19 \\
\hline G2 & $18.45 \pm 4.69$ & B & 11.08 & 26.21 \\
\hline G3 & $29.08 \pm 6.48$ & A & 21 & 38.5 \\
\hline G4 & $18.71 \pm 4.85$ & B & 12.94 & 27.17 \\
G5 & $30.83 \pm 5.58$ & A & 24.6 & 38.3 \\
\hline G6 & $13.48 \pm 2.12$ & C & 10.45 & 17.69 \\
\hline G7 & $12.36 \pm 2.26$ & C & 9.3 & 16.4 \\
\hline
\end{tabular}

$\mathrm{n}=8$. Means \pm Standard deviations (SD). Mean values with same letters are not statistically significant at $\mathrm{P}<.05$. 
study, Santos et a ${ }^{20}$ compared the effect of $\mathrm{CHX}$ with NS as a control, which is not the condition in our study. As adsorption and release of $\mathrm{CHX}$ from tooth surface takes as long as 48-72 hours, with the possible degradation of $\mathrm{CHX}$, delaying of adhesive application for one week might negate its interfering action.

The adverse effect of $\mathrm{NaOCl}$ on the bond strength was clear in this study. This result is in consistence with previous studies. ${ }^{10-14}$ The presence of "protein chloramine-derived radicals"19 in NaOCL-irrigated dentin might result in premature chain termination and incomplete resin polymerization ${ }^{10}$ which leads to reduction in bond strength. Although some resin tags were observed in specimens irrigated with $\mathrm{NaOCl}$ that received immediate bonding (Figure $5 \mathrm{~A}$ ), these tags showed a porous structure (Figure $5 \mathrm{~B}$ ). This porous structure might be attributed to the interfering action of $\mathrm{NaOCl}$ with resin polymerization. Inadequately polymerized resin could be evaporated during SEM preparation leaving the resin tags with porous structure. Delaying the adhesive application for one week

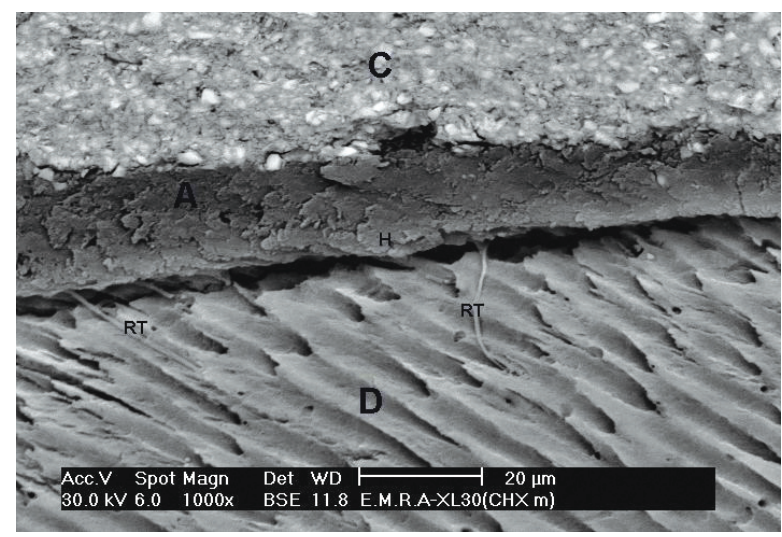

Figure 4. SEM micrograph for G4 (CHX-Immediate). Hybrid layer $(H)$ with few discrete resin tags infiltration (RT). D=Dentin, $\mathrm{A}=$ Adhesive, $\mathrm{C}=$ Composite resin (Original magnification X1000).
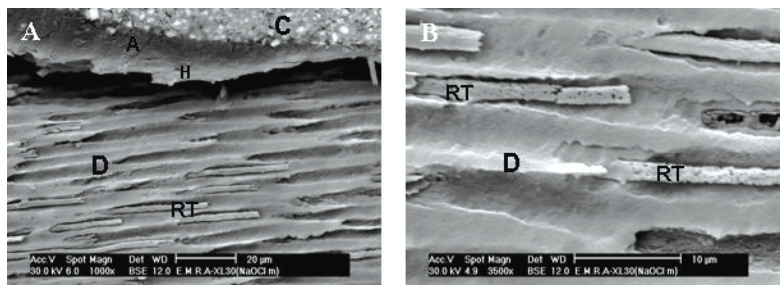

Figure 5. SEM micrograph for $\mathrm{G} 6$ ( $\mathrm{NaOCL}$-immediate) showing. A: An uneven adhesive layer was detected (A). Hybrid layer (H) with some resin tags (RT) and empty tubules are shown (Original magnification X1000). B: Higher magnification of $A$, showed resin tags (RT), which appear with porous structure. $\mathrm{D}=$ Dentin (Original magnification X3500). did not improve the bond strength in specimens irrigated with $\mathrm{NaOCl}$ solution. This could clarify that the action of these protein chloraminederived radicals persisted for more than one week.

\section{CONCLUSIONS}

Within the limitations of this study, delaying the bonding procedures for one week appeared to be beneficial in improving the shear bond strength for the tested single-step self-etch adhesive to coronal dentin especially when NS and $\mathrm{CHX}$ were used as endodontic irrigants. $\mathrm{NaOCL}$ proved to be an incompatible irrigant when used prior to the application of such adhesive. Further studies should be conducted to evaluate the effect of the different irrigants on the resin/coronal dentin bond strength of the contemporary available adhesives.

From the results of this study, if Clearfil $\mathrm{S}^{3}$ bond is intended to be used for restoring endodontically treated teeth, it is preferable to postpone the restorative procedure for one week.

\section{REFERENCES}

1. Kijsamanmith $\mathrm{K}$, Timpawat S, Harnirattisai C, Messer $\mathrm{HH}$. Micro-tensile bond strengths of bonding agents to pulpal floor dentin. Int Endod $J$ 2002;35:833-839.

2. Ray HA, Trope M. Periapical status of endodontically treated teeth in relation to the technical quality of the root filling and the coronal restoration. Int Endod J 1995;28:1218.

3. Weine FS. Nonsurgical re-treatment of endodontic failures. Comp Cont Educ Dent 1995;16:324-335.

4. Vire DE. Failure of endodontically treated teeth: Classification and evaluation. J Endod 1991;17:338-342.

5. Hommez GMG, Coppens CRM, De Moor RJG. Periapical health related to the quality of coronal restorations and root fillings. Int Endod $J$ 2002;35:680-689.

6. Eakle WS. Fracture resistance of teeth restored with class II bonded composite resin. J Dent Res 1986;65:149-153.

7. Belli S, Zhang Y, Pereira PNR, Ozer F, Pashley DH. Regional bond strengths of adhesive resins to pulp chamber dentin. J Endod 2001;27:527-532.

8. Nikaido T, Takano Y, Sasafuchi Y, Burrow MF, Tagami J Bond strengths to endodontically treated teeth. Am J Dent $1999 ; 12: 177-180$ 
9. Ercan E, Özekinci T, Atakul F, Gül K. Antibacterial activity of $2 \%$ chlorhexidine gluconate and $5.25 \%$ sodium hypochlorite in infected root canal: In vivo study. J Endod 2004;30:8487.

10. Lai S, Mak Y, Cheung G, Osorio R, Toledano M, Carvalho R, Tay F, Pashley DH. Reversal of compromised bonding to oxidized etched dentin. J Dent Res 2001;80:1919-1924.

11. Ozturk B, Özer F. Effect of $\mathrm{NaOCl}$ on bond strengths of bonding agents to pulp chamber lateral walls. $J$ Endod 2004;30:362-365.

12. Perdigäo J, Lopes M, Geraldeli S, Lopes G, Garcia-Godoy F. Effect of a sodium hypochlorite gel on dentin bonding. Dent Mater 2000;16:311-323.

13. Vongphan N, Senawongse P, Somsiri W, Harnirattisai C. Effects of sodium ascorbate on microtensile bond strength of total-etching adhesive system to $\mathrm{NaOCl}$ treated dentine. J Dent 2005;33:689-695.

14. Yiu C, Garcia-Godoy F, Tay F, Pashley DH, Imazato S, King $\mathrm{N}$, Lai S. A nanoleakage perspective on bonding to oxidized dentin. J Dent Res 2002;81:628-632.

15. Santos J, Carrilho M, De Goes M, Zaia A, Gomes B, de Souza-Filho F, Ferraz C. Effect of chemical irrigants on the bond strength of a self-etching adhesive to pulp chamber dentin. J Endod 2006;32:1088-1090.

16. Carrilho M, Carvalho R, de Goes M, di Hipólito V, Geraldeli S, Tay F, Pashley D, Tjäderhane L. Chlorhexidine preserves dentin bond in vitro. J Dent Res 2007;86:90-94.

17. Carrilho M, Geraldeli S, Tay F, de Goes M, Carvalho R, Tjäderhane L, Reis A, Hebling J, Mazzoni A, Breschi L, Pashley D. In vivo preservation of the hybrid layer by chlorhexidine. J Dent Res 2007;86:529-533.

18. Hebling J, Pashley D, Tjäderhane L, Tay F. Chlorhexidine arrests subclinical degradation of dentin hybrid layers in vivo. J Dent Res 2005;84:741-746.

19. Hawkins C, Davies M. Hypochlorite-induced oxidation of proteins in plasma: formation of chloramines and nitrogencentred radicals and their role in protein fragmentation. Biochem J 1999;340:539-548.

20. Van Meerbeek V, Van Landuyt K, De Munck J, Hashimoto M, Peumans M, Lambrechts P, Yoshida Y, Inoue S, Suzuki K. Technique-sensitivity of contemporary adhesive. Dent Mater J 2005;24:1-13.

21. Van Landuyt K, Snauwaert J, De Munck J, Coutinho E, Poitevin A, Yoshida Y, Suzuki K, Lambrechts P, Van Meerbeek B. Origin of interfacial droplets with one-step adhesives. J Dent Res 2007;86:739-744.

22. De Munck J, Van Landuyt K, Peumans M, Poitevin A, Lambrechts P, Braem M, Van Meerbeek B. A critical review of the durability of adhesion to tooth tissue: Methods and results. J Dent Res 2005;84:118-132.
23. Perdigao J, Lopes M, Geraldeli S, Lopes GC, Godoy FG. Effect of a hypochlorite gel on dentin bonding. Dent Mater 2000;16:311-323.

24. Frankenberger R, Perdigão J, Rosa BT, Lopes M. "Nobottle" vs "multi-bottle" dentin adhesives: a microtensile bond strength and morphological study. Dent Mater 2001;17:373-380.

25. Asaka Y, Amano S, Rikuta A, Kurokawa H, Miyazaki M, Platt J, Moore B. Influence of thermal cycling on dentin bond strengths of single-step self-etch adhesive systems. Oper Dent 2007;32:72-78.

26. Yuan Y, Shimada Y, Ichinose S, Tagami J. Effect of dentin depth on hybridization quality using different bonding tactics in vivo. $J$ Dent 2007;35:664-672.

27. El-Shamy H. Adhesive remnant index (ARI) and failure mode of two glass ionomer cements to tooth substrates. PhD Thesis 2007; Ain Shams University.

28. Addy M. Antiseptic in periodontal therapy. In: Lindhe J, Karring T, Lang N. Clinical periodontology and implant dentistry. $3^{\text {rd }}$ edition, $2^{\text {nd }}$ printing 1998; Munksgaard, Copenhagen: 461-487.

29. Sodhi R, Grad H, Smith D. Examination by X-ray photoelectron spectroscopy of the adsorption of chlorhexidine on hydroxyapatite. J Dent Res 1992;71:14931497.

30. White RR, Hays GL, Janer LR. Residual antimicrobial activity after canal irrigation with chlorhexidine. $J$ Endod 1997;23:229-231.

31. Leonardo MR, Tanomaru Filho M, Silva LAB, Nelson Filho $P$, BonifacioKC, Ito IY. In vivo antimicrobial activity of $2 \%$ chlorhexidine used as a root canal irrigating solution. $J$ Endod 1999;25:167-171.

32. Erdemir A, Ari H, Güngünes H, Belli S. Effect of medications for root canal treatment on bonding to root canal dentin. $J$ Endod 2004;30:113-116. 